\title{
The role of Pragmatics in English Language Teaching. Pragmatic Competence
}

\author{
Nivis Deda MA \\ University of Shkodra "Luigj Gurakuqi" \\ E-mail: nivisdeda@yahoo.com
}

\author{
Doi:10.5901/ajis.2012.v2n4p63
}

\begin{abstract}
:
Pragmatics is the way we convey the meaning through the communication. The meaning includes verbal and non verbal elements and it varies according to the context, to the relationship between utterers, also to many other social factors. Its dynamic growth makes English an international language that connects people all around the world. As a consequence, English can be regarded as the common focus of all English speakers who do not share a language or a culture. As a matter of fact, English is spoken in different settings and levels of intercommunication. As a result, speakers must know many pragmatic elements in order to avoid inaccuracies and misunderstandings during communication. Such a great usage of English language requires a pragmatic competence which will help all those who speak or learn English as a second language. Thomas defined pragmatic competence as "... the ability to analyze language in a conscious manner." (as cited in Holmes \& Brown, 2007, $p$ 524).Pragmatic competence refers to the ability to comprehend, construct utterances which are accurate and appropriate to the social and cultural circumstances where the communication occurs. Pragmatic competence should be a leading goal for all those who teach English as a second language, which simultaneously represents a challenging task as well.
\end{abstract}

Key words: pragmatic competence, intercommunication, illocution, speech act.

\section{Introduction}

Nowadays English is the language of globalization, international communication, commerce and trade, the music, the media, therefore different motivations for learning it come into act. As Richards (2001) stated, English is no longer viewed as the property of the English-speaking world but it is an international commodity sometimes referred to as English an International Language.

Recent methods and approaches in teaching English as a second language focus on English as a practical tool and world commodity rather than a cultural enrichment. Due to such circumstances, the approach which survived in the new millennium is Communicative Language Teaching. Indeed, the principles of this approach are as follows:

- Language learning is communicative competence

- Learners learn a language through using it to communicate

- Fluency and accuracy are important keys of authentic and meaningful communication.

Many linguists have used the term competence in different contexts to refer to different types of knowledge. The term competence however was originally set out by the father of linguistics Noam Chomsky. In his book 'Aspects of the Theory of Syntax', he defines competence as: "Linguistic theory is primarily concerned with an ideal speaker-listener. In completely homogeneous speech community who knows its language perfectly and is unaffected by such grammatically irrelevant conditions as memory limitations, distractions, shifts of attention and interest, and errors (random or characteristic) in applying his knowledge of the language in actual performance." (Chomsky 1965:3)

Later, Chomsky put the distinction between competence (the speaker's or hearer's knowledge of languages) and performance (the actual use of language in concrete situations). This study put forward the distinction between the knowledge on one hand and the use of this knowledge on the other. However, 
Chomsky did not explain whether this knowledge includes the idea of 'ability'. It seems that Chomsky equated 'competence' with 'knowledge', but he did not present a clear distinction between 'knowledge' and 'the ability to use this knowledge' for communicative purposes.

Language learning came to be seen as a social and cognitive process. As Richards (2001) concludes, Second Language acquisition theory today remains influenced by Chomsky's view of linguistic competence and universal grammar, as well as Vygotsky's view scaffolding process which focuses on the gap between what the learner can do and the next stage in learning which occurs through negotiation.

Canale and Swain (1980) defined communicative competence as a consistence of four aspects: grammatical competence, sociolinguistic competence, discourse competence and strategic competence. According to Canale (1983), grammatical competence refers to mastering the linguistic code of the language that is being learnt; sociolinguistic competence means knowing the sociocultural rules of the use of the second language; discourse competence refers to the ability to select and arrange lexical items and syntactic structures in order to achieve well-formed texts; strategic competence refers to the ability to command verbal and non-verbal devices in order to compensate insufficient mastery or to enhance communication.

Bachman (1990) suggested that language knowledge includes two types of knowledge that a second language learner must internalize:

a) Organizational knowledge, that is knowing how to control the formal structure of a second language so as to produce correct sentences and organize these in texts. It subsumes grammatical and textual knowledge.

b) Pragmatic knowledge, which involves knowing how words and utterances can be assigned specific meanings in context and function according to the user's intentions. This knowledge is also structured in lexical knowledge, functional knowledge and sociolinguistic knowledge.

The above concepts of communicative competence have one thing in their central that is Pragmatics. In fact, Blum-Kulka (1982), underlined the need to train second language learners to specific aspects of particular speech acts in the target language, to perform them, what motivates their performance in certain contexts, therefore when, where, how and with whom they can perform.

\section{Some definitions of Pragmatics as a science}

According to Leech (1974), Charles Morris introduced the first modern definition of pragmatics, and since then many other specialists have continued to conceptualize this branch of linguistics. Morris originally defined pragmatics as "...the discipline that studies the relations of signs to interpreters, while semantics studies the relations of signs to the objects to which the signs are applicable" (as cited in Leech, 1974, p. 172).

Kasper (1993) defined the term as "the study of people's comprehension and production of linguistic action in context" (p. 3). Here, there are included the words action and context, two crucial elements of speech acts in language. Kasper used the term linguistic action which defines the capacity of the learner to produce an utterance. He also put emphasis on comprehension as well as production, a distinction that is particularly relevant for second language learners' daily lives.

Crystal (1985: 240) defined pragmatics as:

... the study of language from the point of view of the users, especially of the choices they make, the constraints they encounter in using language in social interaction, and the effects their use of language has on the other participants in an act of communication."

This definition analyzes pragmatics from the perspective of the users. It takes into account the different choices that speakers are able to make when using the target language, depending on the social interaction of their communication. The notion of choice leads to another aspect into consideration useful to language learners, namely, developing the ability to make the right choices among a variety of pragmatic elements.

Crystal considered pragmatics as the study of the communicative action in its sociocultural context. Thus, it can be said that individuals have some sort of pragmatic competence which allows them to use 
language in different and concrete situations, in varying contexts. Therefore, pragmatic competence is mainly studied at the social level within the limits of speech acts and social acts, interactions or at the interactional level.

\section{Types of competences in the process of language teaching}

As it was mentioned above, communicative approach and the term competence brought into discussion different aspects of the communicative competence; all these aspects are interwoven and they can be included in a broader term, pragmatic competence. As it was stated above pragmatics is defined as a science which studies and considers simultaneously the utterance and the utterer, the action and the intention. In order to understand better the development of pragmatic competence in language teaching, the competence types can be briefly analyzed as the following, based on various linguists 'points of view.

\subsection{Sociolinguistic Competence}

Sociolinguistic competence is the ability to interpret the social meaning of a linguistic item and to decide and use language in an appropriate social meaning for communicative purposes. As Savignon (1983:37) mentions, "Sociolinguistic competence is the knowledge of socio-cultural rules of discourse and language. It requires 'an understanding of the social context in which language is used: the roles of participants, the information they share, and the function of interacting."

As Erton (2007) further explains in his article Applied Pragmatics and Competence Relations in Language Learning and Teaching, the sociolinguistic information which the speakers convey to each other share a pragmatic competence which helps them to interpret and act in different situations by making use of different contextual clues. There are also included components like: 'culture' and 'interaction', which reflect the fundamental concepts of verbal and non-verbal communication.

\subsection{Interactional Competence}

Kramsch (1986: 367) in her article From Language Proficiency to Interactional Competence defines the term 'interaction' as ". . . interaction entails negotiating intended meanings, i.e., adjusting one's speech to the effect one intends to have on the listener. It entails anticipating the listener's response and possible misunderstandings, clarifying one's own and the other intentions and arriving at the closed possible watch between intended, perceived, and anticipated meanings."

As Erton (2007) concludes, considering this definition, it can be said that interactional competence not only makes the use of structural rules of language, but also runs the psycho-linguistic and socio-linguistic functions of language which help to provide accuracy and clarify to the mutual comprehension of the speech acts covered in the course of a conversation. Thus, the so called 'functional competence', involves the ability to establish the tie between the question and its equivalence in particular real life situation, recognizing the speaker's intention by evaluating his/her body language, awareness of the semiotic symbols used, types of social interaction (i.e. introducing, greeting, farewell, etc.), the communicative functions of language, acting accordingly and appropriately.

\subsection{Cultural Competence}

Lyons (1990:302) defines the term culture as, "Culture may be described as socially acquired knowledge: i.e. as the knowledge that someone has by virtue of his being a member of a particular society." Thus, cultural competence can be defined as the ability to understand and use language in a way that would be understood by the members of that culture. 
According to Le Page (1978:41), "When we come to the central question of 'competence' we have to ask: 'What is it an individual needs to know, in order to operate as a member of this society?' A society only exists in the competence of its members to make it work as it does; a language only exists in the competence of those who use and regard themselves as users of that language, and the latter competence is the essential mediating system for the former."

Here, the term competence is regarded as a living social action which effects social behaviour in order for the latter to be achieved clearly and to avoid misunderstandings.

\subsection{Communicative Competence}

H.G. Widdowson (1989:135) described the communicative competence, ". . . communicative competence is not a matter of knowing rules for the composition of sentences and being able to employ such rules to assemble expressions from scratch as and when occasion requires. It is much more a matter of knowing a stock of partially pre-assembled patterns, formulaic frameworks, and a kit of rules, so to speak, and being able to apply the rules to make whatever adjustments are necessary according to contextual demands. Communicative competence in this view is essentially a matter of adaptation, and rules are not generative but regulative and subservient."

Thus, as Widdowson said, communicative competence is the ability to put language for communicative purposes. The communicative competence considers language as a tool used for communication. This competence focuses on the development of four language skills, and on the correlation between the skills.

Canale and Swain (1980) considered the term communicative competence as a mediator which refers to the relationship between grammatical competence (the knowledge of the rules of language) and the sociolinguistic competence (the knowledge of the rules of language use).

\subsection{Strategic Competence}

Canale and Swain (1980) defined strategic competence as an ability which deals with the knowledge of language and the ability to use this knowledge effectively and appropriate to purpose in order to take an active part in communicative interaction.

As Erton (2007:64) further clarifies, "... the strategic competence is the link that ties 'everything' together. A typical example for this case can be: if you are late to a meeting and if you need to find a good excuse, the white lie that you utter at that time is a product of your strategic competence which reflects a criteria of the competence types that the language user has. However, under the title strategic competence the critical and the creative aspects of the human mind can also be considered as well." thinking.

Thus, under such speaking terms, there is accordance between strategic competence and critical

Richards (1998:95) says, "Critical reflection refers to an activity or process in which experience is recalled, considered and evaluated, usually in relation to a broader purpose. It is a response to a past experience and involves conscious recall and examination of the experience as the basis for the evaluation and the decision-making and as a source for planning and action."

As Richards mentioned as well, critical thinking is part of an evaluation of language and information, both being based on experience and knowledge. There might be included other factors such as: accuracy, coherence, unity. As such, this process can be considered as a strategy between questions and answers, stimulating critical thinking.

\subsection{Discourse Competence}

Erton (2007: 64) says "... discourse competence deals with the ability to arrange sentences into cohesive structures. In Discourse Analysis, the term discourse competence is studied within the limits of conversational 
interaction where language is considered a tool for successful communication. Such interactional patterns can be of great variety."

As Akmajian (1997:369) exemplifies, "There are many forms of discourse and many forms of talkexchange. Letters, jokes, stories, lectures, sermons, speeches, and so on are all categories of discourse; arguments, interviews, business dealings, instruction, and conversations are categories of talk exchanges. Conversations (and talk-exchanges in general) are usually structured consequences of expressions by more than a single speaker."

Therefore, the development of discourse competence helps the language learner to gain insight by experiencing different interactional patterns in varying socio-cultural and physical contexts.

\subsection{Pragmatic Competence}

Pragmatic competence refers to the ability to comprehend, construct, and convey meanings that are both accurate and appropriate for the social and cultural circumstances in which communication occurs.

Blackman (cited in Barron, 2003, p. 173) identified pragmatic competence as one element of communicative competence, placing pragmatic competence as part of illocutionary competence, which is a combination of speech acts and speech functions along with the appropriate use of language in context.

In simple terms, Pragmatics is about culture, communication, and in the case of second languages, about intercultural communication. In order for second language learners to acquire pragmatic competence, they need to acquire cultural understanding and communication skills.

According to Watzlawick, on Novinger (2001, p.19) "We cannot communicate. All behavior is communication, and we cannot behave." Every behavior or action can be considered communication, and each of our actions reflect our cultural background including our opinions towards gender, religion, sexual orientation, lifestyle, politics and even personal space.

\section{Why teach pragmatics in language classes}

The study of pragmatics explores the ability of language users to match utterances with contexts in which they are appropriate; in Stalnaker's words, pragmatics is "the study of linguistic acts and the contexts in which they are performed" (1972, p. 383). The teaching of pragmatics aims to facilitate the learners' sense of being able to find socially appropriate language for the situations that they encounter. Within second language studies and teaching, pragmatics encompasses speech acts, conversational structure, conversational implicature, conversational management, discourse organization, and sociolinguistic aspects of language use such as choice of address forms.

As Bardovi-Harlig (1996) advocate, teaching pragmatics because quite simply, observation of language learners shows that there is a demonstrated need for it and that instruction in pragmatics can be successful.

Kasper \& Schmidt (1996) explain further that learners show significant differences from native speakers in the area of language use, in the execution and comprehension of certain speech acts, in conversational functions such as greetings and leave takings, and in conversational management such as back channeling and short responses.

The goal of instruction in pragmatics is not to insist on conformity to a particular target-language norm, but rather to help learners become familiar with the range of pragmatic devices and practices in the target language. With such instruction learners can maintain their own cultural identities (Kondo) and participate more fully in target language communication with more control over both intended force and outcome of their contributions

The first issue is to make language available to learners for observation. Some speech acts, such as invitations, refusals, and apologies often take place between individuals, and so learners might not have the opportunity to observe such language without being directly involved in the conversation. 
As Gallow points out, even maintaining a conversation in English requires a certain amount of knowledge underlying responses that prompt a speaker to continue, show understanding, give support, indicate agreement, show strong emotional response, add or correct speaker's information, or ask for more information; Berry also discusses the importance of learning how to take turns, and demonstrates that listening behaviors that are polite in one language, may not be polite (or recognizable) in another.

The second issue is salience. Some necessary features of language and language use are quite subtle in the input and not immediately noticeable by learners; for example the turns that occur before speakers actually say "goodbye" and the noises that we make when encouraging other speakers to continue their turns are of this type. Differences in making requests by asking "Can I" (speaker-oriented) versus "Can you" (hearer-oriented) might not be immediately salient to learners. By highlighting features of language and language use, instruction can inform the learner.

\section{The role of Pragmatic Competence in the process of teaching and learning a second language}

"We don't learn from experience. We learn from reflecting on experience." (Dewey, 1938, p. 13) Dewey makes a simple but powerful point: experience is not the source of learning, but rather it is reflection on this experience.

The four skills in language learning; reading writing, listening and speaking do not occur in isolation in communicative texts or activities. In order to shape a good pragmatic competence for the language learner, the following should be taken into consideration.

1. The goals and the objectives of a language course should be designed to meet the needs of the language learner to help them develop and improve their communicative competence. Since the primary goal of learning a second language is to provide fluency and accuracy in written and spoken modes of communication, first, the language teacher and the learner should pay attention to design communicative activities which would help to develop the communicative competence. Stern (1983:346) summarizes 'competence' in language teaching as:

a) The intuitive mastery of the forms of language.

b) The intuitive mastery of the linguistic, cognitive, affective and sociocultural meanings, expressed by the language forms.

c) The capacity to use the language with maximum attention to communication and minimum attention to form.

d) The creativity of language use.

Obviously, the term competence invites both the teacher and the learner to develop linguistic and sociolinguistic skills, in order to achieve complete and accurate communication.

2. The language teacher should design the course material to engage the learners in the pragmatic, coherent and functional uses of language for communicative purposes. As Erton (1997:7) claims, "The functional study of language means, studying how language is used. For instance, trying to find out what the specific purposes that language serves for us, and how the members of a language community achieve and react to these purposes through speaking, reading, writing and listening."

The pragmatic competence of the learner must be well developed; consequently he or she will be able to conduct communication with accuracy. The development of coherence and the ability to react in different situations show a good level of functional competence. The grammar of the target language should not be taught in isolation with its use. The learned should be able to put his or her knowledge of language into practice.

3. There are a number of activities useful for the development of pragmatic competence. Moreover, they should raise the learners' awareness of the importance of such competence in the process of acquiring the target language. As Mey (1993:185-6) states, "Linguistic behaviour is social behaviour. People talk because they want to socialise, in the widest possible sense of the world: 
either for fun, or to express themselves to other humans, or for some 'serious' purposes, such as building a house, closing a deal, solving a problem and so on."

Thus, Mey claims that, language is a tool for human beings to express themselves as social creatures and the language used in that particular context is important in terms of linguistic interaction that takes place. "Such a context naturally presupposes the existence of a particular society, with its implicit and explicit values, norms, rules and laws, and with all its particular conditions of life: economic, social, political and cultural." admits Mey (1993:186-7).

\section{Conclusion}

The purpose of the application of different teaching and learning activities is to help students become more effective, fluent and successive communicators in the target language. As Harlow (1990:348) states, ". . . most importantly, both teachers and textbooks alike need to emphasise to the learner that language is composed of not just linguistic and lexical elements; rather, language reflects also the social context, taking into account situational and social factors in the act of communication."

Since pragmatic competence is a combination of these factors, the development of the pragmatic ability should be accepted as one of the primary teaching goals.

Students will be able to act different communicative patterns, they will find themselves active and involved in concrete acts in the classroom.

Pragmatic competence will secure them good levels of grammatical and functional competences as well. They will react fluently, coherently and accurately. What is more, pragmatic competence will urge their critical thinking.

\section{References}

Akmajian, A. and Demers R. A., et.al. 1997. Linguistics: An Introduction to Language and Communication. Massachusetts: The MIT Press.

Barron, Anne. 2003. Acquisition in Interlanguage Pragmatics. Learning how to do things with words in a study abroad context. Philadelphia: John Benjamins Publishing Company.

Brown, H. Douglas. 2007. Teaching by Principles: An Interactive Approach to Language Pedagogy. New York: Pearson Education.

Campbell, R. and R. Wales. 1970. "The Study of Language Acquisition." In J. Lyons (ed.) New Horizons In Linguistics. Harmondsworth: Penguin.

Canale, M. 1983. "From Communicative Competence to Communicative Language Pedagogy." In J. C. Richards and R. W. Schmidt (eds.) Language and Communication. London: Longman.

Chomsky, N. 1965. Aspects of the Theory of Syntax. Cambridge, Mass.: The MIT Press.

Crystal, D. 1985. A Dictionary of Linguistics and Phonetics. 2nd edition. Oxford: Blackwell.

Erton, I. 2007. Applied Pragmatics and Competence Relations in Language Learning and Teaching, Journal of Language and Linguistic Studies, Vol.3, No.1, April 2007

Farrell, Thomas. 1998. "Reflective Teaching: the Principles and Practises." English Teaching Forum October-December (No:4).

Harlow, L. Linda. 1990. Do They Mean What They Say? Sociopragmatic Competence and Second Language Learners. The Modern Language Journal 74.

Heath, S. B. 1983. Ways With Words: Language, Life and Work in Communities and Classrooms. New York: Cambridge University Press.

Kasper, Gabriele. 1993. Interlanguage Pragmatics. Cary, NC: Oxford University Press, Incorporated.

Kramsch, Claire. 1986. "From Language Proficiency to Interactional Competence" The Modern Language Journal Vol.70, Issue 4, 366-372.

Le, Page, R. B. 1978. "Sociolinguistics and the problem of Competence." In V. Kinsella (ed.) Language Teaching and Linguistics: Surveys. Cambridge: Cambridge UP.

Lyons, John. 1990. Language and Linguistics. Cambridge: Cambridge UP.

Mey, L. Jacob. 1993. Pragmatics: An Introduction. Oxford: Blackwell Publishers. 
Richards, Jack C 2001. Communicative Language Teaching Today. New York: Cambridge University Press.

Savignon, S. J. 1983. Communicative Competence: Theory and Classroom Practice. Reading, MA: Addison-Wesley Publishing Company.

Stern, H. H. 1983. Fundamental Concepts of Language Teaching. Oxford: Oxford UP. 70

Thomas, Jenny. 1995. Meaning In Interaction: An Introduction to Pragmatics. London: Longman.

Widdowson, H. G. 1989. "Knowledge of Language and Ability for Use." Applied Linguistics 10.

Young, R. F. 2002. "Discourse Approaches to Oral Language Assessment" Annual Review of Applied Linguistics. (22), 243-262. 